\title{
Apparent monoclonal origin of lymphocytes and plasma cells infiltrating ocular adnexal amyloid deposits: report of 2 cases
}

\author{
D. R. LUCAS, FIONA KNOX, AND S. DAVIES \\ From the Departments of Ophthalmology and Pathology of the University of Manchester
}

SUMMARY Two cases of primary amyloidosis involving the orbit and lid respectively are described. Immunoperoxidase staining of the associated infiltrate of lymphocytes and plasma cells showed a clear preponderance of cells carrying $\lambda$ light chains in one case and $\kappa$ in the other. The predominant heavy chains were IgA and IgG respectively. It is suggested that these cases are 'burnt out' local plasmacytomas.

Although not common, amyloid infiltration of the lid and conjunctiva has been reported on many occasions. But similar involvement of the orbit is rare. ${ }^{1}$ In most cases there is no history or evidence of any pre-existing local or systemic disease. Clinically the condition appears as a slowly progressive painless swelling involving lids or orbit.

The pathogenesis of the amyloid deposits remains obscure, but a consistent pathological feature is infiltration by lymphocytes, plasma cells, and foreign body giant cells. ${ }^{2}$ Though these cells may represent a reaction to the deposition of amyloid, there is a strong possibility that the plasma cells may play a role in its deposition. This being so, the question arises whether or not they are 'neoplastic.' The boundary between orbital 'pseudotumours' in which amyloid is laid down and primary localised amyloidosis in which cellular infiltration is absent or minimal is not clear, ${ }^{3}$ and a local plasmacytoma of the conjunctiva in which amyloid was later deposited has been reported. ${ }^{4}$

Identifying the immunoglobulins carried by lymphocytes and derived cells is of value in differentiating pseudotumours from lymphomas in that the former tend to have a heterogeneous population while the latter often show a predominance of cells carrying a particular light chain. $^{5-7}$ The present paper reports on the immunoglobulin labelling of cells associated with amyloid deposits in 2 cases in which the orbit and eyelid were respectively involved.

Correspondence to Dr D. R. Lucas. Department of Pathology. New Medical School, Oxford Road. Manchester M13 9PT.

\section{Material and methods}

\section{CASES}

1. A 78-year-old man presented with a 2-year history of a painless swelling in the right upper lid which was now causing ptosis to the extent of closing the eye. On examination a smooth hard mass was palpated in the right upper orbit; this protruded into the upper lid from behind and displaced the globe downwards. Right upward movement was limited. Right optic atrophy was noted. Orbital $x$-ray was normal, and CT scan showed no extension of the tumour behind the globe.

The patient had had a myocardial infarction 3 years previously and complained of shortness of breath but was otherwise well. Haemoglobin, white cell and platelet counts, and plasma urea and electrolyte levels were normal at this time.

At operation the tumour was poorly encapsulated and extended back over the globe for some distance. The tumour was therefore removed in a piecemeal manner. At follow-up a month after operation the lesion was thought to be returning: a firm mass, measuring approximately $1 \mathrm{~cm}$ in length was palpable under the orbital rim. The patient was lost to further follow-up.

2. A 46-year-old woman presented with thickening of the left lower lid resulting in entropion, which was subsequently corrected. Eighteen months later she was readmitted with recurrence of thickening of the left lateral canthus and tarsal plate for which a tarsal plate biopsy was performed. 


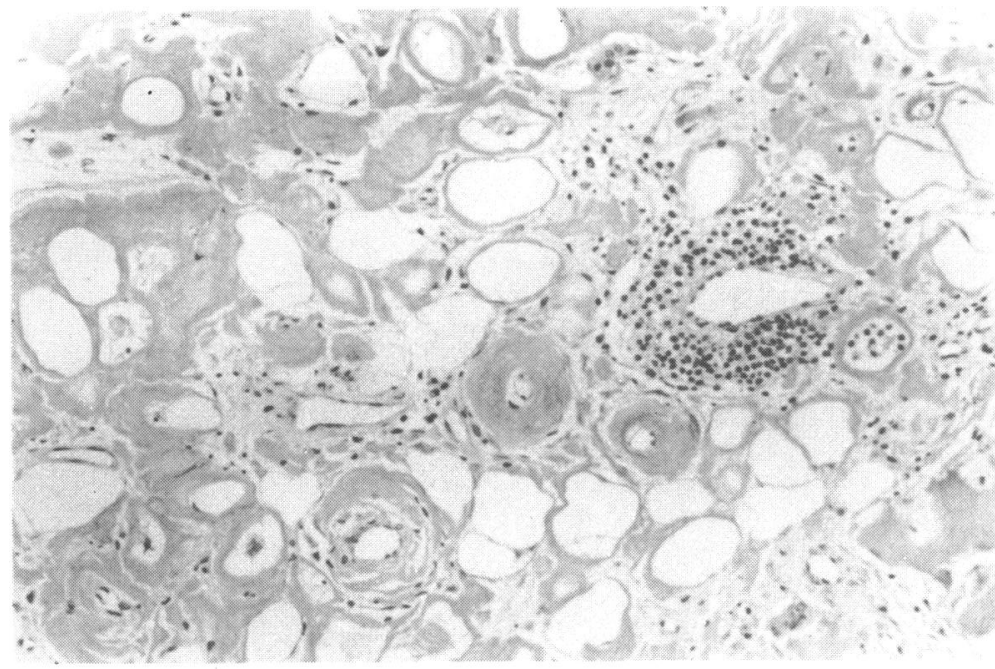

Fig. 1 Case 1. Amyloid in adipose tissue and walls of small blood vessels and cuffing of a small blood vessel by lymphocytes. (PAS $\times 145)$.
Subsequent investigations showed normal haematological indices and bone marrow. Immunoglobulin levels lay within the normal range and no paraprotein was present. Light chains were not detected in the urine. Chest $x$-ray was normal, and no evidence of myeloma was seen in the dorsal spine. She was otherwise well apart from recurrent urinary frequency and frequent ectopic beats.

\section{METHODS}

The tissue was fixed in unbuffered $10 \%$ formalin and embedded in ester wax for normal histology and paraffin wax for immunoperoxidase staining. Tissue for electron microscopy was postfixed in buffered glutaraldehyde (after recovery from the paraffin block in case 2). The PAP method ${ }^{8}$ was used to demonstrate immunoglobulins. Rabbit antisera for human IgG, M, A, and D 150 types and $\kappa$ and $\lambda$ light chains were obtained from Dako except anti-IgE, which was supplied by Behring. The IgG and $M$ antisera were diluted to $1 / 2000$, the $\operatorname{IgA}, \mathrm{D}$, and $\mathrm{E}$ to $1 / 1000$, and the anti- $\kappa$ and $\lambda$ to $1 / 3000$. Most sections were counterstained by the sodium sulphate-alcian blue method for amyloid.' In case 1 sections were exposed to the antisera both with and without prior trypsinisation.

\section{Results}

\section{CASE 1}

Pathological appearances. The specimen consisted of 2 pieces of firm fibrofatty tissue measuring $3 \cdot 0$ $\mathrm{cm} \times 2.5 \mathrm{~cm} \times 1.5 \mathrm{~cm}$ and $2.5 \mathrm{~cm} \times 0.5 \mathrm{~cm}$ and a hard translucent nodule $1.3 \mathrm{~cm} \times 0.5 \mathrm{~cm}$.

Microscopically the specimen consisted predominantly of structureless masses of eosinophilic material together with some fatty tissue and striated muscle. The hyaline material stained with Congo red and by the PAS method. It was birefringent and showed green dichroism after Congo red staining. Numerous foreign body giant cells were present, and there were foci of lymphocytic infiltration. Occasional plasma cells were identified in these foci, and there was cuffing of small blood vessels by lymphocytes.

The hyaline material was observed being laid down in rings in fatty tissue and also in striated muscle fibres (Fig. 1). A small area of bone formation was present (Fig. 2).

Electron microscopy. The hyaline material showed

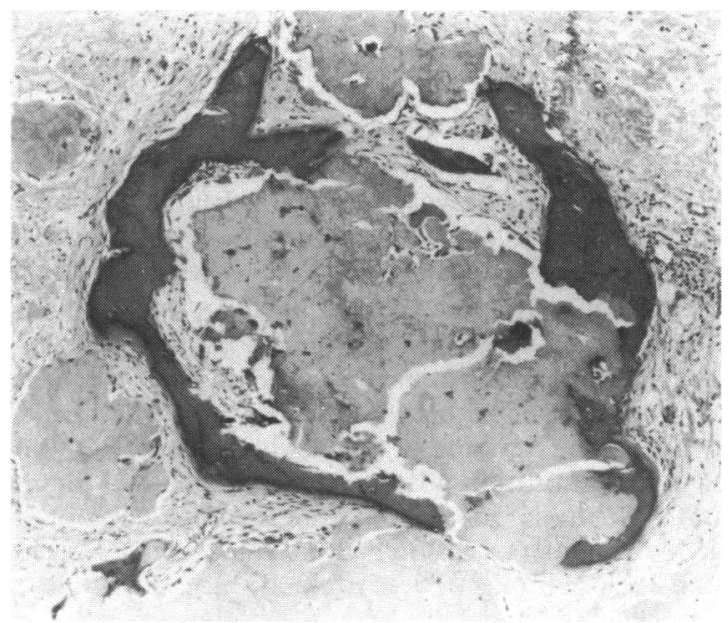

Fig. 2 Case 1. Bone formation between masses of amyloid ( $H$ and $E, \times 54)$. 
Fig. 3 Case 1. Electron micrograph showing typical bundles of amyloid fibrils. $(\times 38000)$.

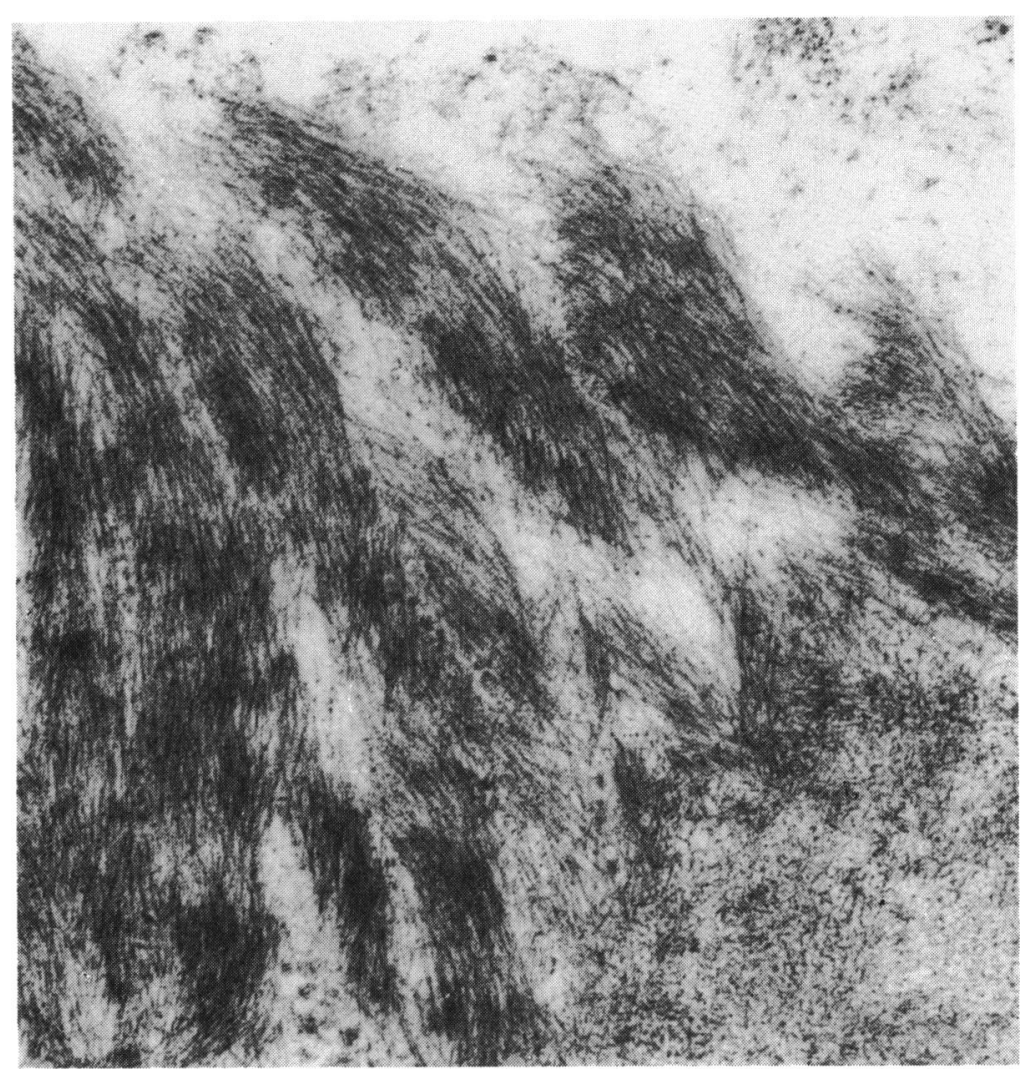

interlacing bundles of non-branching fibrils typical of amyloid (Fig. 3).

Immunoperoxidase staining. Staining of substantial numbers of the lymphocytes and plasma cells occurred only with antisera for $\lambda$ light chains (Fig. 4) and $\operatorname{IgA}$. Labelled cells were not randomly distributed but tended to occur round the periphery of focal aggregates. It was therefore difficult to estimate the number stained with any accuracy, but in some aggregates it appeared to approach $50 \%$. Only occasional cells stained with antisera for $\kappa$ light chains (Fig. 5), IgG, IgM, IgE, or IgD. Prior treatment with trypsin appeared to increase the number of cells carrying IgA but otherwise did not affect the results significantly. Staining of the amyloid with or without prior trypsinisation was erratic. With anti- $\kappa, \lambda, \operatorname{IgG}$, and IgM the larger masses were unstained except at their margins. Occasional small masses engulfed in giant cell cytoplasm were stained. Occasional giant cells also showed faint diffuse cytoplasmic staining with these antisera. The hyaline material was stained by the sodium-alcian blue counterstain.
CASE 2

Pathological appearances. The specimen consisted of an irregular strip of tissue, $1.5 \mathrm{~cm} \times 0.5 \mathrm{~cm} \times 0.4 \mathrm{~cm}$.

Microscopically the tissue was composed of circumscribed masses of almost acellular hyaline material which stained positively by the PAS method and showed red-green dichroism with Congo red. Small arteries and arterioles in the vicinity also showed hyaline infiltration and mural thickening. A few foreign body giant cells were seen in relation to the material.

In the adjacent stroma was a mass of lymphocytes, plasma cells, and some histiocytes. Numerous Russell bodies and several small islands of hyaline material were present in the infiltrate (Figs. 6a,b). No epithelium was present in the specimen.

Electron microscopy. The hyaline material had the typical unbranched fibrillary structure of amyloid.

Immunoperoxidase staining. At the periphery of focal aggregates nearly $100 \%$ of the lymphocytes and plasma cells stained for the $\boldsymbol{\kappa}$ chain, though islands of unstained cells were present (Fig. 7). Somewhat 


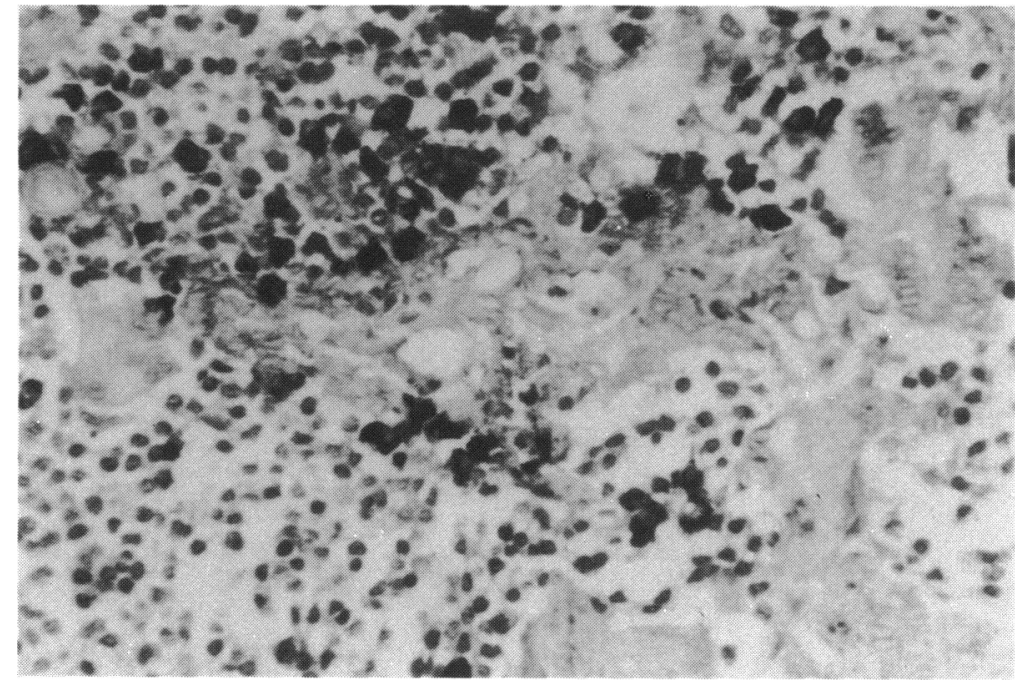

Fig. 4 Case 1.

Immunoperoxidase staining for $\lambda$ light chains, substantial group of heavily stained cells. $(\times 357)$. fewer stained for IgG, and the staining was less dense (Fig. 8). Less than $1 \%$ of cells stained for the $\lambda$ chain (Fig. 9), while occasional cells also stained for IgA and IgM. No cells stained for IgD and IgE.

The amyloid was generally unstained. Some giant cells showed weak staining with anti- $\lambda$ and $\kappa$ sera.

The hyaline material was stained by the sodium sulphate-alcian blue counterstain.

\section{Discussion}

By 1979, 14 cases of orbital amyloidosis had been published and these have been fully reviewed. ${ }^{10}$ Since then a further 2 cases have appeared. ${ }^{11}{ }^{12}$ Computed tomographic scanning contributed to the diagnosis of these cases. The ages of the 16 cases ranged from 24 to 78 , and 11 were females. Deposits of amyloid were not discovered elsewhere in these cases, but in a rather unusual case in a girl of $9^{13}$ amyloidosis involved the inferior nasal meatus, the vocal cords, hard palate, and inner aspect of the nasal bridge, whence it extended into the upper and lower eyelids to the level of the orbital rims.

Amyloid (or hyaline) infiltration of the eyelid has been described and reviewed. ${ }^{214-18}$ The cases appear to show a similar age and sex distribution to those arising in the orbit.

Deposits in ocular adnexal structures are very

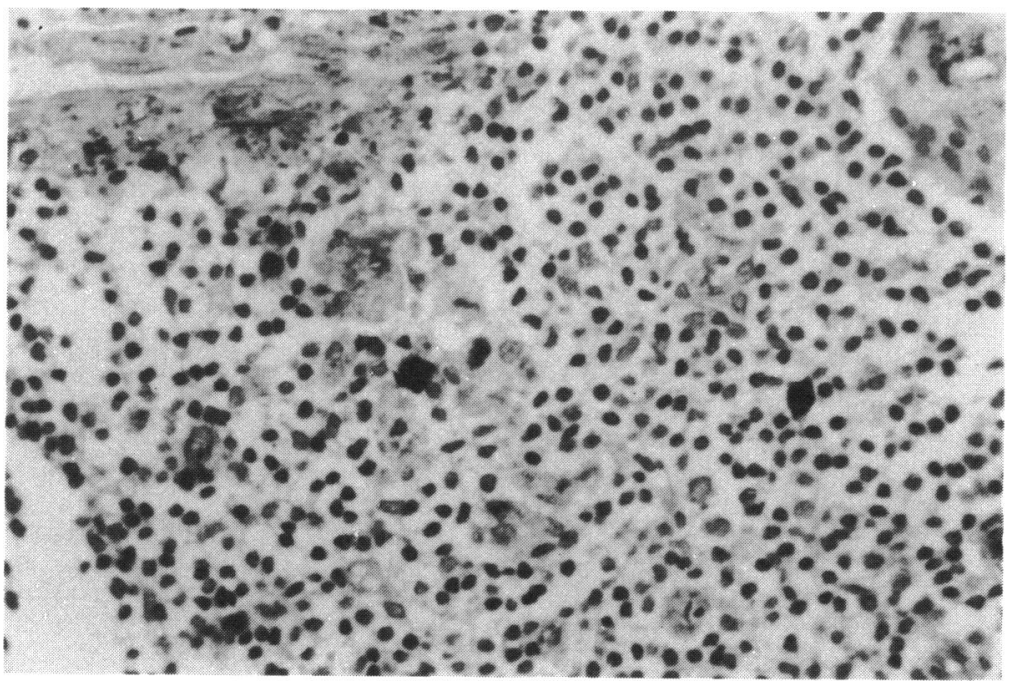

Fig. 5 Case 1.

Immunoperoxidase staining for $\mathrm{\kappa}$ light chains; only 2 positively stained cells in field comparable to that shown in Fig. 4. (×357). 


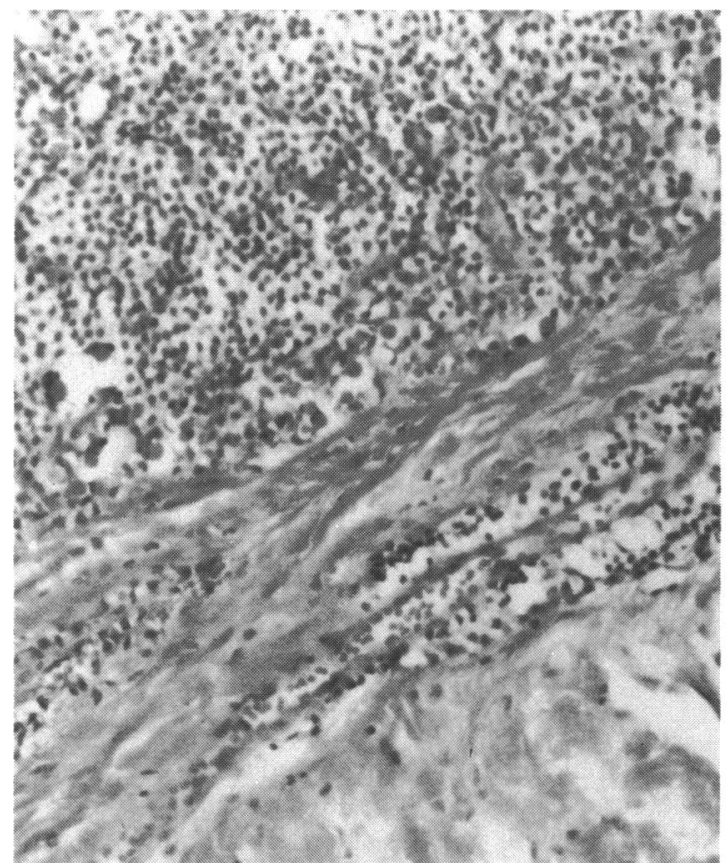

$6 a$

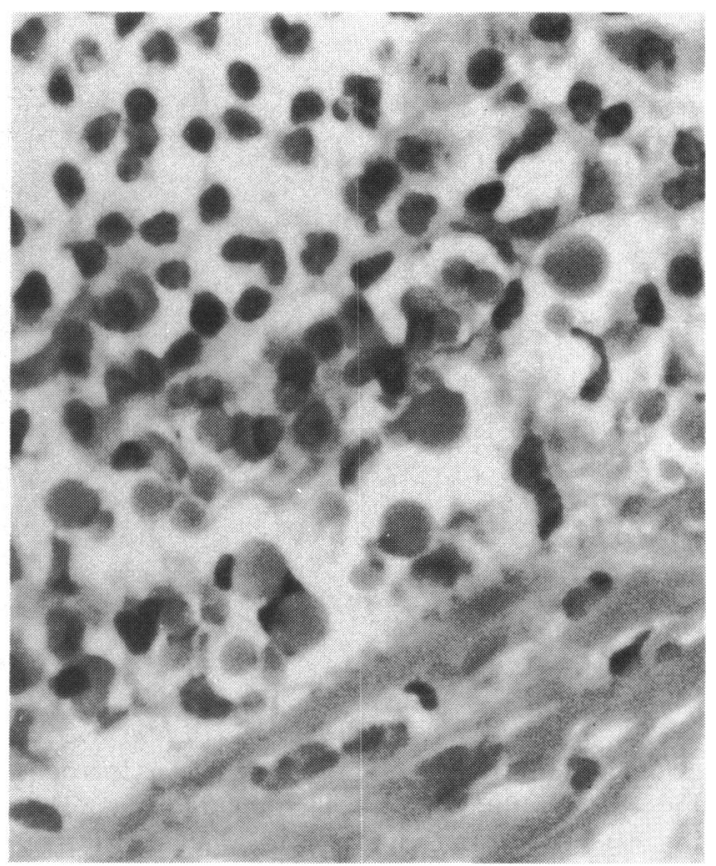

$6 b$

Fig. 6 Case 2. (a) Heavy infiltrate of lymphocytes and plasma cells separated from mass of amyloid by fibrous band. $(\times 178)$. (b) Same field, numerous Russell bodies mainly along fibrous band. $(\times 750)$.

uncommon in systemic amyloidosis. ${ }^{18}$ By contrast deposits in the central retinal artery and vitreous body are more often seen in association with systemic amyloidosis than in its absence. ${ }^{19}$

The principal pathological features are similar whatever the location of the adnexal deposits. There is deposition of amyloid both as large masses and in the walls of small blood vessels and in adipose tissue. Giant cells are present in varying numbers, and a cellular infiltrate composed of lymphocytes and plasma cells is usually present, though its density may vary considerably and is sometimes minimal. ${ }^{12}$ The 2 cases described here show these general features but differ in minor particulars. In case 1 the giant cell

Fig. 7 Case 2 .

Immunoperoxidase staining for $\kappa$ light chains, substantial group of heavily stained cells at periphery of a lymphoid focus. $(\times 357)$.

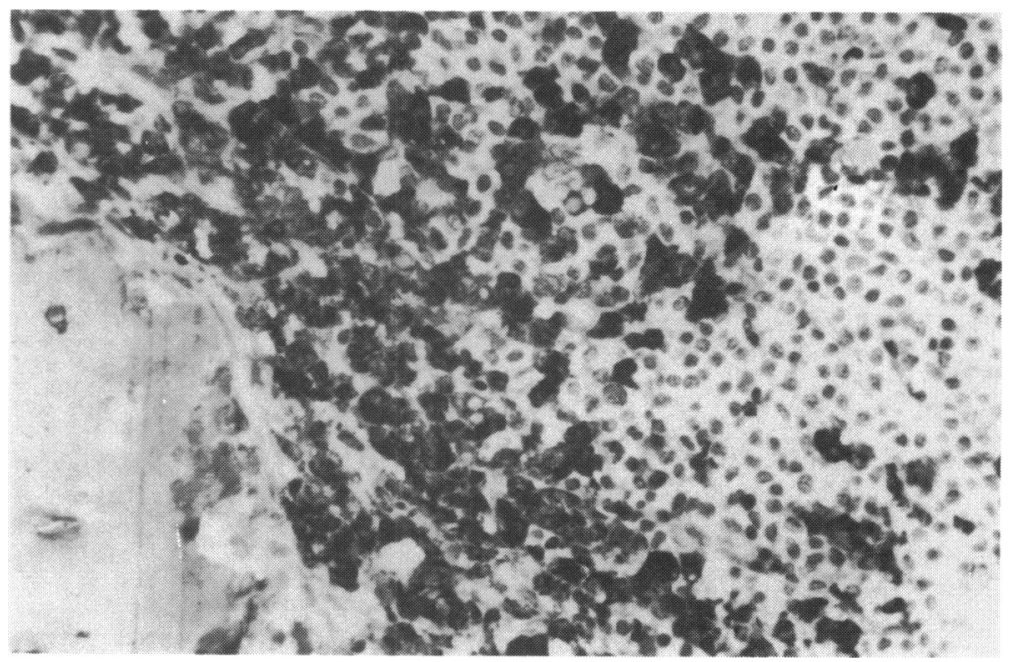




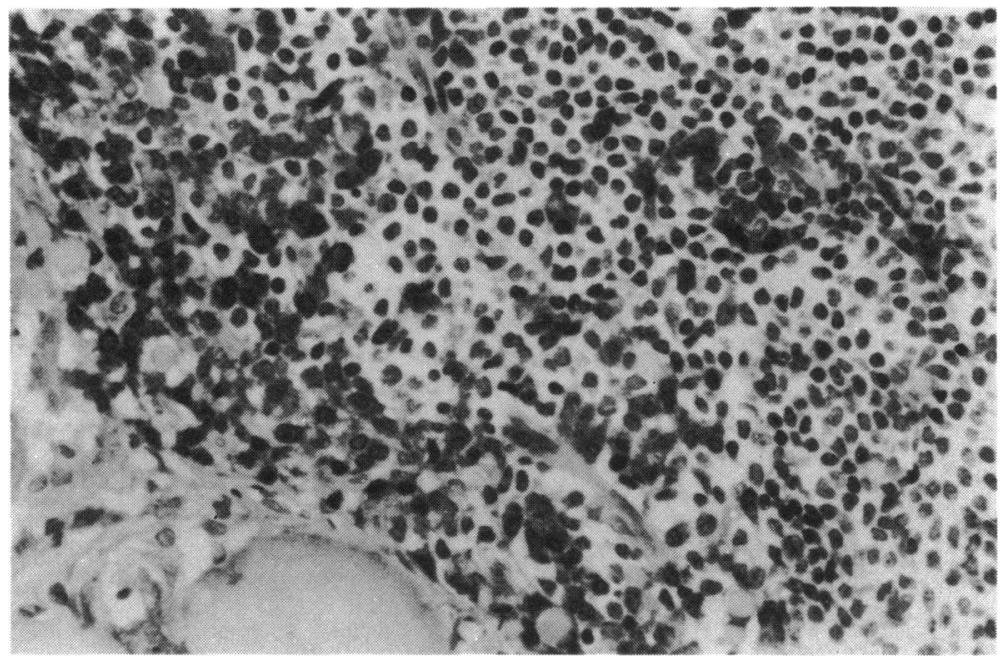

Fig. 8 Case 2.

Immunoperoxidase staining for IgG, substantial group of cells showing positive staining mainly at periphery of lymphoid focus. $(\times 357)$.

reaction is particularly conspicuous; the cellular infiltration is predominantly lymphocytic and not very dense. Bone formation is unusual, but has been described previously. ${ }^{20}$ In case 2 the giant cell reaction was minimal and the cellular infiltrate denser and predominantly plasmacytic. The very numerous Russell bodies are also unusual but have been noted previously. ${ }^{21}$

The electron microscope findings serve to confirm that the material has the typical fibrillary structure of amyloid, but fixation was too poor to allow any conclusions to be drawn as to the relationship of the fibrils to component tissue cells, which is at present somewhat controversial. ${ }^{1213}$

The reaction of the amyloid itself and associated giant cells to immunoperoxidase staining was too erratic for conclusions to be drawn.

The principal interest of the 2 cases is the apparent monoclonality of the cellular infiltrate associated with the amyloid. Thus, those cells that were labelled showed an overwhelming preponderance reacting for $\lambda$ chains and $\operatorname{IgA}$ in case 1 and for $\kappa$ chains in $\operatorname{IgG}$ in case 2 . A greater proportion of the infiltrate reacted in case 2, probably because of the higher proportion of plasma cells. No previous immunoperoxidase studies appear to have been made on comparable cases, but in a case of orbital amyloidosis a suspension of cells obtained was stained with fluorescein-labelled antisera and found to show $30 \%$ of the cells reacting for IgG, $24 \%$ for $\kappa$ chains and $4 \%$ for $\lambda$ chains. ${ }^{21}$ Since

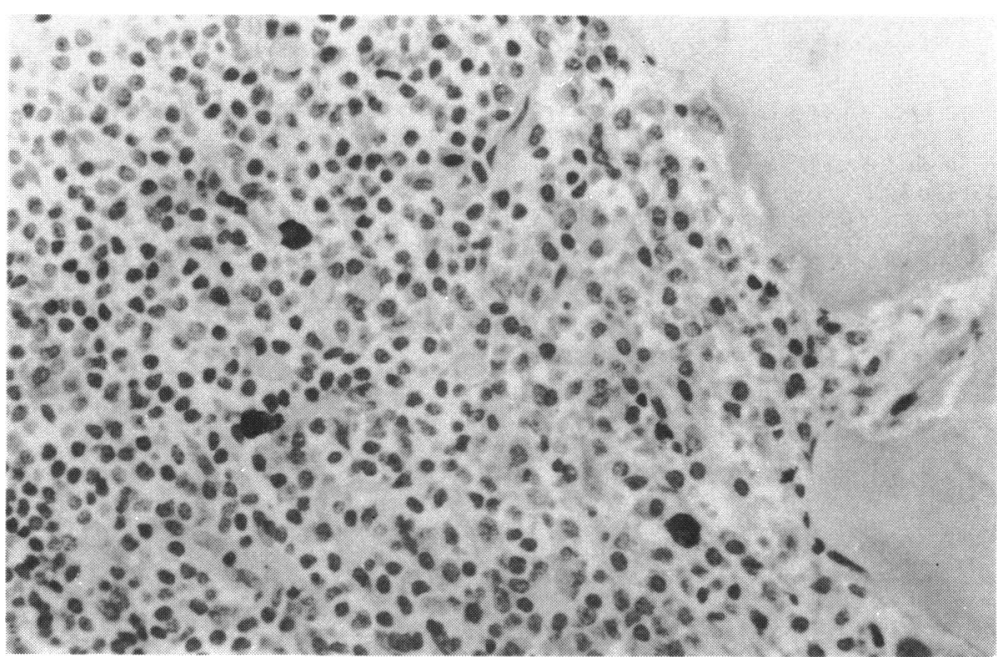

Fig. 9 Case 2.

Immunoperoxidase staining for $\lambda$ light chains; only 3 stained cells in field comparable to that shown in Fig. 7. (×357). 
in normal serum $65 \%$ of the immunoglobulin molecules are of the $\kappa$ type and $35 \% \lambda \lambda_{,}^{22}$ it is surprising that this was not considered by the author to indicate monoclonality.

The general pathogenesis of amyloid deposition has recently been comprehensively reviewed, ${ }^{23-25}$ as also has its deposition in relation to the eye and adnexa. ${ }^{26}$ The relative importance of immunocytes and macrophages remains controversial. Making the assumption that the lymphocytes and plasma cells associated with the amyloid infiltrates have a primary pathogenetic role, the apparent monoclonality of the populations is consistent with the view expressed by Glenner ${ }^{25}$ that they represent 'burnt out' local extramedullary plasmacytomas. That there is no clear-cut boundary between orbital amyloidosis and pseudotumours ${ }^{3}$ does not rule out such a conclusion because plasmacytic pseudotumours are difficult to distinguish from true extramedullary plasmacytomas except on the basis of the monoclonality or otherwise of their constituent cells. ${ }^{27}$

In view of the large local population of lymphocytes and plasma cells in the tarsal conjunctiva it is not surprising that the conjunctiva and lids are involved more frequently than the orbit. It is noteworthy that in case 1 , in which the process apparently started in the orbit, the predominant heavy chain carried by the infiltrating cells was $\operatorname{IgA}$, which is consistent with derivation of the progenitor cell or cells from the conjunctiva.

Note added in proof: Case 2 has developed a localised thickening of the eyelid at the same site after an interval of 2 years and 4 months. Tissue excised for cosmetic reasons and examined histologically contained amyloid with very few infiltrating cells.

Thanks are due to Mr I. M. Strachan, Mr S. K. Sharma, and Dr W. C. Walker for providing clinical details and to Miss K. Hughes and Mrs L. Thomas for skilled technical assistance. Professor W. L. Ford kindly read the manuscript and made helpful comments.

\section{References}

1 Duke-Elder S. Amvloidosis of the orbit. Sustem of Ophthalmologv. London: Henry Kimpton. 1974: 3 (2).

2 Knowles DM II. Jakobiec F. Rosen M. Howard G. Ocular amvloidosis. Surv Ophthalmol 1975: 19: 367-84

3 Henderson JW. Orbital Tumors. Philadelphia: Saunders. 1973.
4 Glass R. Scheie HG, Yanoff M. Conjunctival amyloidosis arising from a plasmacytoma. Ann Ophthalmol 1971; 3: 823-5.

5 Levy R. Warnke R. Dorfman RF. Haimovich J. The monoclonality of human B-cell lymphomas. J Exp Med 1977; 145: 1014-8.

6 Warnke R. Levy R. Immunopathology of follicular lymphomas. N Engl J Med 1978; 298: 481-6.

7 Knowles DM. Jakobiec F. Halper AP. Immunological characterisation of ocular adnexal lymphoid neoplasms. Am J Ophthalmol 1979; 87: 603-19.

8 Burns J. Background staining and sensitivity of the unlabelled antibody-enzyme (PAP) method. Comparison with the peroxidase labelled antibody sandwich method using formalin fixed paraffin embedded material. Histochemistry 1975; 43: 291-4.

9 Lendrum AC, Slidders W, Fraser DS. A study of renal hyaline amyloidosis and diabetic fibrinous vasculosis with new staining methods. J Clin Pathol 1972; 25: 373-96.

10 Nehen JH. Primary localised orbital amyloidosis. Acta Ophthalmol (Kbh) 1979; 57: 287-95.

11 Cohen MM. Lessell S. Amyloid tumours of the orbit. Neuroradiology 1979; 18: 157-9.

12 Finlay KR, Rootman J. Dimmick J. Optic atrophy in primary orbital amyloidosis. Can J Ophthalmol 1980; 15: 189-92.

13 Kaiser-Kupfer MI. McAdam KPWJ, Kuwabara T. Localised amyloidosis of the orbit and upper respiratory tract. Am J Ophthalmol 1977; 84: 721-8.

14 Ashton N. Rey A. Hyaline infiltration of the eyelid. Br J Ophthalmol 1951: 35: 125-33.

15 Richlin JJ. Kuwabara T. Amyloid disease of the evelid and conjunctiva. Arch Ophthalmol 1962: 67: 139-42.

16 Halasa AH. Amyloid disease of the eyelid and conjunctiva. Arch Ophthalmol 1965; 74: 298-301.

17 Smith ME. Zimmerman L. Amyloidosis of the eyelid and conjunctiva. Arch Ophthalmol 1965; 75: 42-51.

18 Brownstein MH. Elliott R. Helwig E. Ophthalmologic aspects of amvloidosis. Am J Ophthalrnol 1970; 69: 423-30.

19 Ferry AP. Lieberman TW. Bilateral amyloidosis of the vitreous bodv. Arch Ophthalmol 1976:94: 982-91.

20 Hameed S. Nath K. Bone formation in the tarsal plate associated with amyloidosis following trauma. Am J Ophthalmol 1960; 49: 814-5.

21 Jensen OA. Bilateral amyloidosis of the orbit. Ophthalmologica 1976; 173: 70-8.

22 Roitt IM. Essential Immunology. Oxford: Blackwell, 1977.

23 Scheinberg MA. Cathcart ES. New concepts in the pathogenesis of primary and secondary amyloid disease. Clin Exp Immunol 1978: 33: 185-90.

24 Glenner GG. Amyloid deposits and amyloidosis: the $\beta$ fibrilloses. Part 1. N Engl J Med 1980; 302: 1283-92.

25 Glenner GG. Amyloid deposits and amyloidosis: the $\beta$ fibrilloses. Part 2. N Engl J Med 1980; 302: 1333-43.

26 Doughman DJ. Ocular amyloidosis. Surv Ophthalmol 1968: 13: 33-42.

27 Khalil MK. Huang S. Viloria J. Duguid WP. Extramedullary plasmacytoma of the orbit: case report with results of immunocytochemical studies. Can J Ophthalmol 1981; 16: 39-42. 